\title{
The Separately Housed Undergraduate Library Versus the University Library
}

\begin{abstract}
The need to accommodate a growing undergraduate student population on the university campus is of serious concern. The differences between university and undergraduate book collections are evident in the former's commitment to a research-oriented program which because of its bulk contains materials that are seldom consulted, extensive range in the complicated card catalog file, and the appointment of personnel qualified to serve scholars and handle complex reference tasks. This has led some librarians to doubt if the undergraduate student can best be served by university library facilities. As an alternative many have adopted the concept of separately housed undergraduate libraries composed of carefully selected collections of materials, a card catalog tailored to the needs of undergraduates, and the selection of specially trained professional librarians. This paper attempts to examine these assumptions and to offer an alternative solution.
\end{abstract}

$\mathrm{T}$ HE RATIONALE underlying the planning of library facilities on a university campus requires some elaboration. A basic problem is the diverse nature of the community to be served. Because of differences between college and university library book collections and physical facilities one may reasonably ask if the undergraduate student in the university environment can be offered or provided with library services that are as effective as those available in a separately housed library for undergraduates. A growing number of institutions apparently are convinced that a university library is inappropriate for the undergraduate, presumably because the enormous book collection will overwhelm him. The problem of college student use of the library collection has been the topic of

Dr. Burke is Associate Director, The Catholic University of America Press, Washington, D.C. numerous published reports without any uniform solutions. Some proposals call for large-scale investments in new separately housed undergraduate libraries. Harvard constructed an independent building, the Lamont Library, and printed a catalog of the undergraduate book collection. Cornell University designed the new Olin Library for research, and redesigned the old Uris $\mathrm{Li}$ brary facilities to provide a separate building for undergraduate students. The extent to which the book collections and periodical holdings are duplicated or geographically separated in favor of graduate use is difficult to assess. Whether the plans encompass a separately housed undergraduate library building, altered older buildings, a rearrangement of the book holdings or special services for undergraduates, the aim is to serve students in the most effective way. A number of universities 
have been exploring the problem and the varying solutions.

Any librarian in preparing a program statement for new library facilities to serve the needs of both undergraduates, graduates, and an increasingly scholarship-conscious faculty, can only hope to make decisions that are valid. It appears that the trend is toward a pattern of a separate college library operating within the framework of a university library system. The implied assumption is that the best situation for undergraduates is a separately housed undergraduate library. To what extent this is a valid assumption needs examination.

The differences between a university and a college library are several. A university is committed to research programs reflected in extensive collections of monographs and scholarly treatises. This is obvious in the sciences, but even in the humanities a collection on Shakespeare or John Milton will encompass extensive studies well beyond the ken of an undergraduate. On two counts, sheer bulk and quality, he may be baffled. Often the magnitude of a collection forces the librarian to make it a closed collection, thereby denying the wonderful privilege of free access to books. The card catalog of a university library offers another stumbling block, since it must exploit in detail the extensive range of research materials for the benefit of scholars. In addition, the personnel who staff a university library may be better suited by temperament to serve scholars and their complex reference problems than the needs of the undergraduates.

In considering these characteristics of a university library, with its large collection of seldom-used materials, its size, its complicated card catalog, and its specially trained personnel, one may justly ask if the undergraduate can make effective use of a university library considering his prior training and present needs. The alternative is to set up a sep- arately housed undergraduate library consisting of those books he will probably have to use, and be able to use, with a smaller and more convenient card catalog, and a library staff trained for the college program. Educators and librarians continue to analyze library programs for college students in the hope of discovering or designing at least ground rules that may be adapted to various situations.

In spite of increasing emphasis on the library playing an active role in the college curriculum, it sometimes seems there is more talk than actual implementation; where systems are presently operating, there is need for valid evaluations of results. There is need to examine the problem as it relates to undergraduates in a manner that will assist in planning a library program of genuine and fruitful educational nature for college students.

There are several facets to this total problem: some practical, as the physical accoutrements and arrangements within the library building or an independent building; some theoretical, as training students in use of the library, providing facilities, materials and personnel to assist these trained users, and planning for the stimulus or motivation for student use of the facilities. The practical problems are resolved largely by compromise between the ideal and the real as represented by such factors as the actual size and shape of a building and the funds available. The theoretical problems are more difficult and complicated. Some librarians propose to base plans for future library facilities and educational programming on the idea of training and inducing students to use the library and providing a book collection and staff adequate for the student's educational needs. Whatever his future, whether he goes on to graduate studies or terminates with a bachelor's degree, the student will be prepared to make libraries an integral part of his adult life. 
Regardless of size, any university book collection presents problems not only to the undergraduates but to research scholars as well. It is easy to indicate the difficulties encountered in using any large library; it is also important to recognize its virtues, especially those that may be of particular value for its undergraduates. A university library possesses all kinds of books found in a college library, but with greater numbers and variety. The library personnel is composed of subject specialists who, taken as a group, possess a deeper bibliographical knowledge than the considerably smaller college library staff. And there are some positive values to be found in a more complete university public card catalog. Possibly some merit may be found in bringing a research library with its highly skilled personnel and large card catalog to an undergraduate instead of developing separate undergraduate facilities. The solution may not be to tailor a program to accord with the student's limitations in library training, but to make every effort to train every college student in the use of books and libraries in relation to his educational needs. It remains to state these educational needs in detail.

The educational needs of the college student must be related to the aims, purposes, and functions of the institution. In the undergraduate curricular design of some universities it is planned that all students will receive an education founded on the liberal arts tradition. In practical terms, this encompasses three educational goals: first, an extensive knowledge and understanding of the history of man and his cultural achievements; second, the development of the necessary intellectual attitudes, habits, and skills for the formation of an able, informed, articulate, and contributing member of society and for his continued intellectual growth after formal education ceases; and third, the acquisition of a sense of values requisite to the final goal of all human development, growth in wisdom. Thus the graduate should acquire knowledge, skills, habits, and attitudes enabling him to perform competently and fruitfully in the material, social, intellectual, and spiritual environment of his post-college years.

Since the reading of books is still the most effective instrument for learning yet developed, the liberal arts program envisions a sweeping educational potential of the college library that goes beyond the limited concept of a combination study hall and place for dispensing of a group of required reading assignments. The faculty is expected to awaken the intellectual curiosity of the student; the extensive reading of many books becomes increasingly important in the teaching process. The center is the individual learner who will be encouraged to engage in the learning process voluntarily and individually. As decision-making is brought closer to the student, the college can adopt policies that extend responsibility to the undergraduate, who will have to fend for himself in a matter of years.

The college library is tailored to facilitate the attainment of the educational needs of its patrons; it accomplishes its role in cooperation with the instructional corps. The first library function is to acquire, process, and make available the materials, printed and otherwise, necessary to the student body and to make provisions for materials necessary for the pursuance of advanced study of faculty members.

In relation to these functions, a university library is undoubtedly in a better position than a separately housed undergraduate library. The vexing problem to be solved concerns the extent to which students have the ability to use collections and to actually exploit the facilities. Even where special undergraduate libraries and/or library instruction programs have been in operation much 
is still to be effected. Both librarians and educators are unhappy that students do not utilize and enjoy fully the library facilities provided for them.

Is it possible for a student to accomplish the three-fold objectives of the liberal arts program, yet be ignorant of the library's role or its use? As to a knowledge and understanding of man's cultural attainments and the development of a sense of values, it would appear that students have demonstrated their ability to achieve these ends through faculty lectures and a minimum of reading assignments. Without extensive use of books or libraries it is questionable whether students can develop intellectual attitudes and skills, become enlightened, informed and active individuals in society, and continue their self-directed learning throughout their lives.

It is generally conceded that skill in the use of the library is being neglected or ineffectively taught in spite of agreement that this skill is essential in formal education as well as in preparation of self-directed learning after graduation. There are some commendable orientation programs now in operation. Some utilize sound films, some instructors make library assignments within their specific courses; some schedules include required or elective courses in library usage. What appears to be desired is a deeper knowledge and understanding of books and libraries to prepare students to pursue independent programs of learning that may place a floor but never a ceiling on the ambitions of any student.

A liberal arts program assumes that in curriculum planning, course objectives be so clearly stated as to be of genuine assistance to the student in selecting desirable learning experiences. A unique feature of this program could be the bold assertion that a knowledge of the university library and its bibliographical operations and skill in making total use of it constitute a major discipline in the total curriculum. Each department could assume an obligation to develop this art of library knowledge and skill in its area. Creativity in both instructors and students could be stimulated. Without infringing upon the responsibility for covering definite materials within the framework of a schedule, the approach of the faculty and reaction of the student should be unhampered enough to permit individual development. This freedom could not be merely permissiveness; it would rather be the expansion of free will founded upon intelligence and selfdiscipline. For the student this would mean independent study in the university library and promotion of study in depth for elite students.

Such a program encompassing the concept of library knowledge and skill as one of the arts can succeed only if it is not only accepted but believed in and promulgated by administration and faculty alike for the inspiration and motivation of the student body must come from them. Any dramatic and exciting educational adventure can be ruined or impaired by either the administration and/or faculty dragging their feet. Possibly the greatest consequence of contemporary education is an abiding appreciation of the value of candid self-criticism. The present program involves basic improvements that appear necessary. The effective advocacy of this educational enterprise must spring from a chorus of many voices-administration, faculty members, and librarians; each individual voice must be strong and clear, not mere lip service but an expression of deep conviction. 